\title{
ARTIGOS
}

\section{FLOW CYTOMETRIC QUANTITATION OF PHAGOCYTOSIS IN HEPARINIZED COMPLETE BLOOD WITH LATEX PARTICLES AND CANDIDA ALBICANS}

\author{
Jesús M. Egido and Juan Viñuelas
}

\begin{abstract}
We report a rapid method for the flow cytometric quantitation of phagocytosis in heparinized complete peripherial blood (HCPB), using commercially available phycoerythrin-conjugated latex particles of $1 \mu \mathrm{m}$ diameter. The method is faster and shows greater reproducibility than Bjerknes' (1984) standard technique using propidium iodide-stained Candida albicans, conventionally applied to the leukocytic layer of peripherial blood but here modified for HCPB. We also report a modification of Bjerknes' Intracellular Killing Test to allow its application to HCPB.
\end{abstract}

Key-words: Phagocytosis. Flow cytometry. Latex particles. Candida albicans.

The phagocytic capacity of granulocytes 11 was until recently quantitated by extracting the leukocytic layer of peripheric blood, incubating it with Candida albicans and estimating phagocyto sis through staining and examination under the light microscope13. The introduction of flow cytometry led to the development of more objective methods: in 1984, Bjerknes 5 described such a method using Candida albicans, with similar sensitivity to that obtained using the classical method. Bjerknes' test has since been applied in various experimental contexts6 816 17. In related studies2 10, Staphylococcus aureus has been used for the measurement of both phagocytosis and hydrogen peroxide production, with similar results.

Bjerknes' test is conventionally applied to the leukocytic layer of peripherial blood. Here, we used heparinized complete peripherial blood (HCPB), to preveny the need for a cell separation step. We compared flow cytometric quantitation of phagocytosis using: a) propidium iodide-stained Candida albicans and b) commercially available phycoerythrinconjugated $1 \mu \mathrm{m}$ diameter latex particles. Both tests were modified for a one-hour incubation period.

We are currently applying our modification of Bjerknes' test in routine analysis of the phago cytic capacity of polymorphonuclear leucocyte (PMNs) in peripherial blood of patients with immune disturbances.

Department of Microbiology and Inmunology, Santiago University, Spain. Department of Inmunology, Hospital Xeral, Santiago, Spain.

Address to: Dr. J. Egido. PO Box 8121, 28080 Madrid, Spain.

Recebido para publicação em 17/01/96.

\section{MATERIAL AND METHODS}

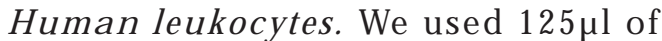
heparinized complete human peripheral blood (from $3 \mathrm{ml}$ of blood containing $0.05 \mathrm{ml}$ of heparin lithium salt at $10 \mathrm{IU} / \mathrm{ml})$, less than $3 \mathrm{~h}$ postextraction, maintained at $20^{\circ} \mathrm{C}$, with a granulocyte count between 3,000 and 5,000 per $\mathrm{mm}^{3}$.

Candida albicans. A sample of human origin was cultured in Sabouraud-chloramphenicol agar (Bio-Merieux $\left.{ }^{\circledR}\right)$, and a subsample was harvested in PBS, pH 7.4, washed twice for 5 min at 500xg (Beckman J-6B). Viability was determined by trypan blue vital staining in a Neubauer chamber, and by flow cytometry with propidium iodide (PI) staining. Only batches with greater viability than $95 \%$ were used.

Opsonization was carried out, when required, by incubating $5 \mathrm{ml}$ of human pooled serum with $1 \mathrm{ml}$ of Candida suspension (250 x 107 cells $/ \mathrm{ml}$ ) for $45 \mathrm{~min}$ at $37^{\circ} \mathrm{C}$.

Fixation was carried out by mixing $70 \%$ ethanol with the Candida suspension (45:5 $\mathrm{v} / \mathrm{v}$ ) and incubating overnight at $-20^{\circ} \mathrm{C}$. This fixation method was compared with three others, using an alkalin cation fixative, Triton $0.1 \%$ and Triton $0.5 \%$. Viability was determined by PI staining and Epics Profile II (Coulter ${ }^{\circledR}$ ) cytometre.

Propidium iodide labelling was carried out by incubating 100 $\mathrm{pl}$ of the Candida suspension (both opsonized and non-opsonized) for 30 min with one of a series of mixtures containing $20,40,80,160,240,400$ or $600 \mu \mathrm{g} / \mathrm{ml}$ of PI (in volumes of between 50 and $400 \mu \mathrm{l}$ ) and 100 $\mathrm{\mu l}$ of RNAse $(1 \mathrm{mg} / \mathrm{ml})$. Flow cytometry showed 
Egido JM, Viñuelas J. Flow cytometric quantitation of phagocytosis in heparinized complete blood with latex particles and Candida albicans. Revista da Sociedade Brasileira de Medicina Tropical 30:441-446, nov-dez, 1997.

the $400 \mathrm{\mu g} / \mathrm{ml}$ concentration to be most effective (data not show). Aliquots of the suspensions containing Candida labelled with PI at this concentration were stored at $-20^{\circ} \mathrm{C}$ until use.

Candida phagocytosis test (CPT). A mixture

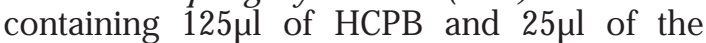
Candida suspension (containing 1 x 107 PIlabelled cells $/ \mathrm{ml}$, fixed with $70 \%$ ethanol as described above) was incubated at $37^{\circ} \mathrm{C}$ with continuous mechanical stirring for 30, 60, 90 and $120 \mathrm{~min}$, and then fixed using the Epics QPrep leukocyte preparation system (Coulter®) prior to flow cytometry. Parallel experiments, all with 60 min incubation, were run with 15, 10 and $5 \mu l$ of the Candida suspension. Phagocytosis was measured by flow cytometry (Coulter Profile II) of $1 \mathrm{ml}$ samples of the QPrep-fixed HCPB/PI-labelled Candida mixtures, with recording of red fluorescence.

Intracellular killing test (IKT). To determine optimum incubation time for the IKT, twentyfive- $\mu$ l samples of unfixed Candida (1 x 107 cells/ml, viability by trypan blue vital staining $>95 \%$ ) were incubated with $125 \mu \mathrm{l}$ of HCPB at $37^{\circ} \mathrm{C}$ with mechanical shaking for $30,60,90$ or $120 \mathrm{~min}$. Granulocytes were then fixed, and erythrocytes lysed, using the Q-Prep system, and the preparation was washed at 500xg with phosphate-bulfered saline (PBS), $\mathrm{pH}$ 7.4. The pellet was incubated for $5 \mathrm{~min}$ with $1 \mathrm{ml}$ of lysis buffer (2.5\% sodium desoxycholate, $\mathrm{pH}$ 8.7, in sterile distilled water) to lyse granulocytes, then washed twice at 10,000xg with PBS. The pellet was resuspended in $1 \mathrm{ml}$ of PBS then incubated with $50 \mu \mathrm{l}$ of PI $(400 \mu \mathrm{g} / \mathrm{ml})$ and $100 \mu \mathrm{l}$ of RNAse $(1 \mathrm{mg} / \mathrm{ml})$ for $30 \mathrm{~min}$ at room temperature in a darkroom, to allow differentiation of dead and live cells. Analysis was by flow cytometry with measurement of red fluorescence.
Latex phagocytosis test (LPT). One-hundred$\mu \mathrm{l}$ aliquots of $1 \mu \mathrm{m}$ diameter phycoerythrin (PE)-labelled latex particles (Polyscience $\left.{ }^{\circledR}\right) 7$ were washed twice with washing buffer $(0.054$ M glycine/saline, $\mathrm{pH}$ 8.2) at $13,000 \mathrm{xg}$ for 10 min (Beckman Microfuge 11). The pellet was resuspended in $5 \mathrm{ml}$ of washing buffer and sonicated for $30 \mathrm{sec}$ with three $50 \mathrm{~W}$ pulses (Branson Sonifier 250). The concentration of latex particles in this suspension according to the manufacturer's instruction was $9 \times 108$ particles per ml. Opsonization was achieved by adding $200 \mu \mathrm{l}$ of ammonium sulphatepurified immunoglobulins at $25 \mathrm{mg} / \mathrm{ml}$ to $5 \mathrm{ml}$ of the suspension of sonicated latex particles, then incubating at $20^{\circ} \mathrm{C}$ with mechanical stirring for one hour. Following 2 - 3 washes in a washing buffer, the resulting pellet was resuspended in $5 \mathrm{ml}$ of storage buffer $(0.27 \mathrm{M}$ glycine/saline and $0.1 \%$ bovine serum albumin - BSA) and stored at $4^{\circ} \mathrm{C}$. Phagocytosis of both opsonized and non-opsonized particles was quantitated by incubation of 5, 10, 20, 30 and $40 \mu \mathrm{l}$ of this suspension (containing $45 \times 105,9$ x 106, 18 x 106, 27 x 106 and 36 x 106 latex particles respectively) with $125 \mu$ l of HCPB at $37^{\circ} \mathrm{C}$ for $60 \mathrm{~min}$, followed by fixation using the Q-Prep system. Flow cytometry measurement (FCM) was of orange fluorescence.

\section{RESULTS}

Candida phagocytosis test. The fixation method leading to the successful fixation of most Candida cells was with $70 \%$ ethanol at $-20^{\circ} \mathrm{C}$ overnight (Table 1 ); $0.1 \%$ Triton and $0.5 \%$ Triton fixation methods were less effective. With a granulocyte-to-Candida cell ratio of 1:5, cell suspensions which had been labelled with a PI solution of $400 \mu \mathrm{g} / \mathrm{ml}$

Table 1 - Percentage of Candida killed by the various fixatin methods, as determined by FCM ( $\mathrm{p}<0.01)$.

\begin{tabular}{ccccc}
\hline & Control & Ethanola & Alkaline cationb & Triton $0.1 \%$ c \\
\hline Percentage \%e & $9.4 \pm 0.1$ & $90.5 \pm 0.1$ & $14 \pm 0.2$ & $12.8 \pm 0.1$
\end{tabular}

a incubation overnight with $70 \%$ ethanol at $-20^{\circ} \mathrm{C}$; b incubation for 15 min with $0.1 \mathrm{M}$ sodium acetate in a mixture of $10 \mathrm{mM}$ Tris $\mathrm{HCl} \mathrm{pH} 8.0$ and $1 \mathrm{mM}$ EDTA at $30^{\circ} \mathrm{C}$; c incubation for 15 min with $0.1 \%$ Triton X-100 (Sigma ${ }^{8}$ ) in PBS at $30^{\circ} \mathrm{C}$; d incubation for 15 min with $0.5 \%$ Triton $\mathrm{X}-100$ in $\mathrm{PBS}$ at $30^{\circ} \mathrm{C}$; e mean $\pm \mathrm{SD} ; \mathrm{n}=3$.

were found to give the most homogenous fluorescence peak (data no shows). The variation in phagocytosis percentages with different incubation times (Table 2) are in accordance with Bjerknes' results with the leukocytic layer of non-heparinized peripheric blood5. The optimum granulocyte-to-Candida cell ratio was 1:5 (i.e. 25pl of Candida suspension to $125 \mu$ l of $\mathrm{HCPB}$ ), with higher ratios leading to reduced phagocytosis (Table 3 ).

Latex phagocytosis test. Different volumes of a suspension containing $9 \times 107$ latex 
Egido JM, Viñuelas J. Flow cytometric quantitation of phagocytosis in heparinized complete blood with latex particles and Candida albicans. Revista da Sociedade Brasileira de Medicina Tropical 30:441-446, nov-dez, 1997.

Table 2 - Percentage phagocytosis of propidium iodide labelled non-opsonized Candida, as measured by FCM, following periods of incubation with HCPB.

\begin{tabular}{lcccc}
\hline & \multicolumn{4}{c}{ Incubation period (min)a } \\
\cline { 2 - 5 } & 30 & 60 & 90 & 120 \\
\hline Percentage phagocytosisb & $58.8 \pm 6.2$ & $71.7 \pm 11.2$ & $82.3 \pm 8.9$ & $89.5 \pm 6.7$
\end{tabular}

a granulocyte/Candida cell ratio was $1: 5.1$; b mean \pm SD; $\mathrm{n}=10$.

Table 3 - Granulocyte-to-Candida ratios and percentage of phagocytosis obtained with 125 $\mu$ l of HCPB and different volumes of suspension of $70 \%$-ethanol-fixed and PI-labeled Candida cells. Granulocyte count in the HCPB was berween 3,000 and 5,000 per mm 3 .

\begin{tabular}{lccccc} 
& \multicolumn{4}{c}{ Candida (1X108 cells/ml) } \\
\cline { 2 - 5 } volume added & $50 \mu \mathrm{l}$ & $25 \mu \mathrm{l}$ & $15 \mu \mathrm{l}$ & $10 \mu \mathrm{l}$ \\
Grabulocyte: Candida ratio & $1: 10$ & $1: 5$ & $1: 3$ & $1: 2$ & $3 \mu \mathrm{l}$ \\
\% Phagocytosisa & $40 \pm 2.3$ & $73 \pm 4.3$ & $45 \pm 2.7$ & $1: 1$ & $30 \pm 3.2$
\end{tabular}

a mean $\pm \mathrm{SD} ; \mathrm{n}=5$. $(\mathrm{p}<0.01)$.

particles/ml were added to HCPB, with subsequent measurement of phagocytosis (Figure 1). The optimum granulocyte-to-latex particle ratio was 1:32 (20ul of the suspension containing $18 \times 10^{6}$ particles to $125 \mu \mathrm{l}$ of HCPB. The phagocytosis was much higher in HCPB (3ml of blood containing
$0.05 \mathrm{ml}$ of the lithium salt of heparin at $10 \mathrm{IU} / \mathrm{ml}$ ) than in ethylenediaminetetraacetate, tripotassium salt (EDTA)-treated complete peniphenic blood (3ml of blood containing $0.06 \mathrm{ml}$ of EDTA (K3) at $85 \mathrm{~g} / \mathrm{l}$ ), in opsonized (OPS) and non-opsonized particles after $60 \mathrm{~min}$ incubation at $37^{\circ} \mathrm{C}$ (Table 4).
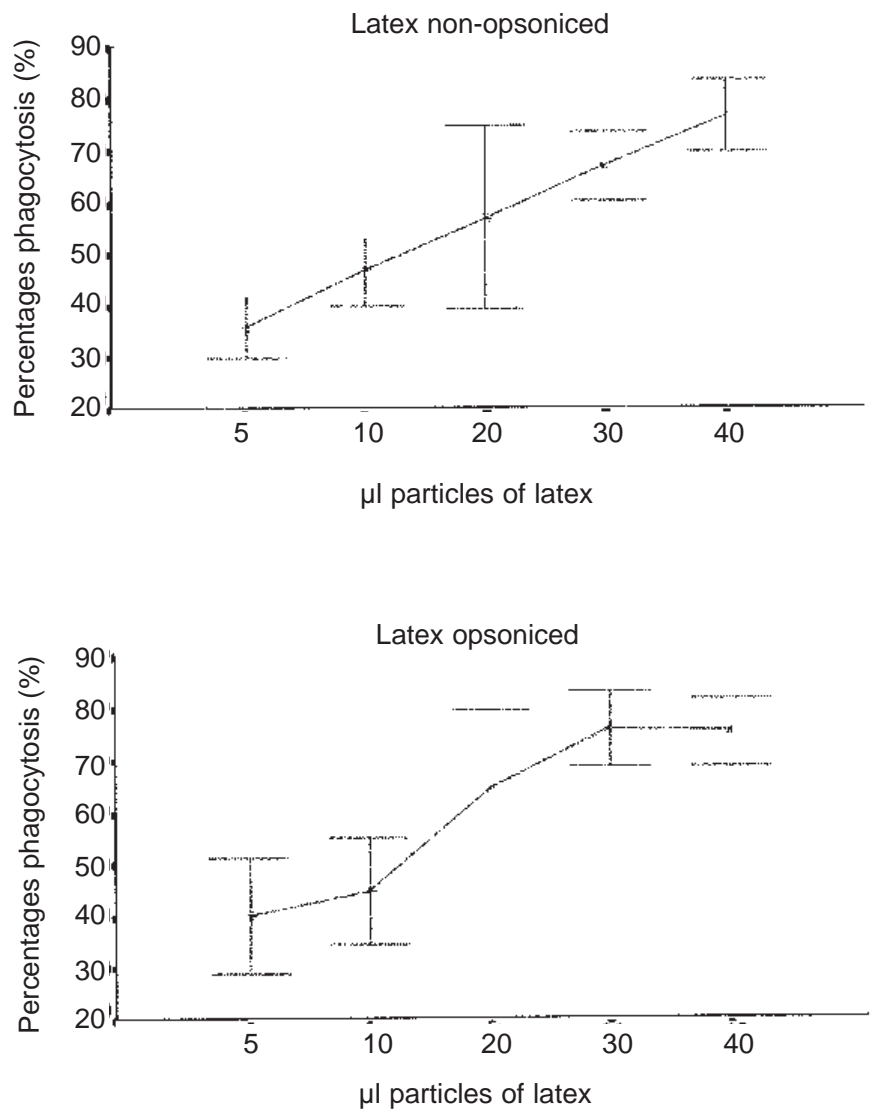

Figure 1 - Latex phagocytosis test: different volumes of a suspension containing 9 X 108 latex particles/ml were added to $\mathrm{HCPB}$, incubated $60 \mathrm{~min}$, with subsequent measurement of phagocytosis (mean $\pm \mathrm{SD} ; \mathrm{n}=20$ ). 
Egido JM, Viñuelas J. Flow cytometric quantitation of phagocytosis in heparinized complete blood with latex particles and Candida albicans. Revista da Sociedade Brasileira de Medicina Tropical 30:441-446, nov-dez, 1997.

Table 4 - Percentage phagocytosis of opsonized and non-opsonized latex particles, as measured
by FCM, following with heparinized blood (0.05ml sodium heparin at 10UI/ml) and EDTA (K)
\begin{tabular}{lcc} 
blood $(0.06 \mathrm{ml}$ as $85 \mathrm{~g} / \mathrm{l})$ & in a total blood volume of 3ml with a $60 \mathrm{~min}$ period of incubation. \\
\hline Percentage \%a & \multicolumn{3}{c}{ Latex } \\
\cline { 2 - 3 } & non-opsonized & opsonized \\
\hline EDTA (K3) blood & $11.3 \pm 0.2$ & $15.3 \pm 0.2$ \\
Heparinized blood & $64.5 \pm 0.2$ & $76.2 \pm 0.2$
\end{tabular}

a mean \pm SD; $\mathrm{n}=3$.

\section{DISCUSSION}

We have adapted Bjerknes' flow cytometric method for the quantitation of phagocytosis, which uses Candida albicans and the leukocytic layer of peripheric blood 45 , for use with HCPB. This obviates the need for prior separation, washing and quantitation of the leukocytic layer, and is thus simpler and more rapid than Bjerknes' original method.

We have also developed an alternative test for the quantitation of phagocytosis in HCPB using commercially available PE-labelled latex particles, of smaller size and more homogenous morphology than Candida cells. Our results show that this test is considerably simpler, faster and more reliable than either Bjerknes' original method or our adaptation of it to $\mathrm{HCPB}$, and we thus propose it as a valid alternative for routine quantitation of the phagocytic capacity of granulocytes in peripheric blood. Clearly, more complex methods are still necessary for detailed studies of patients with phagocytic disturbances1.

Optimum granulocyte-particle ratio was found to be 1:5 in the case of the Candida test, and 1:36 in the case of the latex test.

The Candida test was additionally optimized with respect to incubation time, with the aim of ensuring sufficient phagocytosis to provide a strong fluorescent signal which is clearly differentiated from the background noise due to other forms of granulocyte-particle binding. In other respects, it was found that any departure from the standard incubation conditions $\left(37^{\circ} \mathrm{C}\right.$ with continuous mechanical stirring) led to considerable increases in background noise.

We also attempted to determine the best PI concentration for Candida labelling such that the fluorescence signal was as strong and homogenous as possible. As has been noted in previous studies17, homogeneity of staining is very difficult to achieve. Different batches of Candida cells fixed and stained under identical conditions respond unpredictably to storage, making it necessary to run controls every time the test is required. Likewise, the dispersion of both forward angle light scatter (FALS) and 90-degree light scater (90LS) diagrams were considerable even after filtration and homogenization with low-power ultrasound, giving high variability in granulocyte size once phagocytosis had occurred. All these problems are minimized when PE-labelled latex particles, which stain much more homogenously and have a much more constant size distribution (and consequently scatter diagrams which are easier to interpret) 12 , are used.

Given the possibility that free (nonphagocytosed) labelled particles may cause fluorescence, leading to false positive results, we also ran controls in which suspensions containing labelled Candida cells $(2.5 \times 106$ cells/ml) or latex particles (18 x 106 particles $/ \mathrm{ml}$ ) were treated and subjected to flow cytometry, as in the respective phagocytosis tests (CPT or LPT) but without incubation with blood. Counts of less than $1 \%$ of those obtained in the respective phagocytosis tests were recorded over periods of more than 120s (note that the standard phagocytosis test samples, containing about 15,000 PMNs, require between 90 and 120 s to pass through the cytometer).

Our results confirm that blood treated with EDTA (K3) is not useful for phagocytosis quantitation because of the resulting complexation of calcium and consequent inhibition of calcium-dependent phagocytosis14 15. Our data likewise confirm the absence of phagocytosis by lympocytes.

The intracellular killing test depends upon the maintenance of a live Candida population in order to obtain a suspension of cells with viability greater than $90 \%$. Propidium iodide will only stain those Candida cells with an altered cell wall which permits its diffusion. The two-stage lysis eliminates the problems associated with staining of cell debris, and the false positives which arise as a result. 
Egido JM, Viñuelas J. Flow cytometric quantitation of phagocytosis in heparinized complete blood with latex particles and Candida albicans. Revista da Sociedade Brasileira de Medicina Tropical 30:441-446, nov-dez, 1997.

We propose the use of the latex phagocytosis test for routine screening purposes, since it shows greater reproducibility than the Candida Phagocytosis Test and is less affected by differences in particle size and labelling/ storage conditions. Continued use of Candida for the intracellular killing test is, however, necessary. Under the test conditions described here, we observed no significant differences between phagocytosis of opsonized and nonopsonized latex particles; however, the application of both forms of the LPT during routine screening may be of value in showing up deficiencies in the opsonization capacity of the patient's serum.

\section{RESUMEN}

Se da cuenta de un método rápido para la cuantización del flujo citométrico de la fagocitosis en sangre periférica completamente heparinizada (HCPB), mediante la utilización de partículas de látex phycoerythrin-conjugadas de $1 \mu \mathrm{m}$ de diámetro disponibles comercialmente. El método es más rápido y presenta mayor reproducibilidad que la técnica estandar de Bjerknes' (1984) utilizando propidium iodide-teñida Candida albicans, aplicada convencionalmente a la capa leucocitica de sangre periférica pero modificada por HCPB. Tambien damos cuenta de una modificación de Bjerknes' Intracellular Killing Test para permitir su aplicación a HCPB.

Palavras-chaves: Fagocitosis. Flujo citométrico. Partículas de látex. Candida albicans.

\section{REFERENCES}

1. Ashman RB, Papadimitriou JM. What's new in the mechanisms of host resistance to Candida albicans infection. Pathology Ressearch Practis 186: 527-534, 1990.

2. Bass'e CF, Bjerkness R. The effect of serum opsonins on the phagocytosis of Staphilococcus aureus and zymosan particles measured by flow cytometry. Acta of Pathology, Microbiology and Inmunology Scandinaves 92:51-58, 1894.

3. Bauer K.D. Analysis of proliferation-associated antigens. In: Darzynkiewicz Z, Crissman HA (eds) Methods in cell biology. Flow cytometry v. 33. Academic Press, San Diego, California, p.235, 1990.

4. Bjerknes R. Flow cytometric assay for combined measurement of phagocytosis and intracellular killing of Candida albicans. Journal of Immunological Methods 72:229-241, 1984.
5. Bjerknes R, Bassoe .F, Sjursen H, Laerum OD, Solberg CO. Flow cytometry for the study of phagocytic functions. Revue of Infectious Dissease v. II 1:16-33, 1989.

6. Buschmann H, Winter M. Assessment of phagocytic activity of granulocytes using laser flow cytometry. Journal of Inmunological Methods 124: 231-234, 1989.

7. Fulwyler MJ, McHugh JM. Flow microsphere immunoassay for the quantitative and simultaneous detection of multiple soluble analytes. In: Darzynkiewicz Z. and Crissman HA (eds) Methods in cell biology. Flow cytometry v. 33. Academic Press, San Diego, California, p.613, 1990.

8. Gabrilovich D, Serobrovskaya L. Assessment of phagocytic activity in whole blood using laser flow cytometry. Journal of Inmunological. Methods 140: 289-290, 1991.

9. Goran L, Goran R. Antibodies to proliferating cell nuclear antigen as S-phase probes in flow cytometric cell cycle analysis. Cancer Research 51: 4570-4574, 1991.

10. Hasui M, Hirabagashi Y, Kobayashi Y. Simultaneous measurement by flow cytometry of phagocytosis and hydrogen peroxide production of neutrophils in whole blood. Journal of Inmunological Methods 117: 53-58, 1989.

11. Jordan FL, Wynder HJ, Booth PL, Tomas WE. Method for the identification of brain macrophages/phagocytic cells in vitro. Journal of Neuroscience Ressearch 26:74-82, 1990.

12. Steinkamp R, Ku W H-M, Righini-Cohen G, Simon M. Phagocytosis: flow cytometric quantitation with fluorescent microspheres. Science 215:6466, 1982.

13. Lehrer RI, Cline MJ. Interaction of Candida albicans with human leucocytes and serum. Journal of Bacteriology 98, 996, 1986.

14. Marodi L, Korchak HM, and Johnston RBJr: Mechanisms of host defense against candida species. I Phagocytosis by monocytes and monocyte-derived macrophages. Journal of Inmunology 146: 2783-2789, 1991.

15. Marodi L, Korchak HM, Johnston RBJ r. Mechanisms of host defense against Candida species. II Biochemical basis for the killing of Candida by mononuclear phagocytes. Journal of Inmunology 146: 2790-2794, 1991.

16. Sasada M, Kubo A, Nishimura T, Kakita T, Moriguchi T, Yamamoto K, Uchimo H. Candidacidal activity 
Egido JM, Viñuelas J. Flow cytometric quantitation of phagocytosis in heparinized complete blood with latex particles and Candida albicans. Revista da Sociedade Brasileira de Medicina Tropical 30:441-446, nov-dez, 1997.

of monocyte-derived human macrophages: relationship between Candida killing and oxygen radical generation by human macrophages. Journal of Leukocytes Biology 41:298-294, 1987.
17. Watanabe K, Kagaya K,YamadaT, and FukazawaY. Mechanism for Candidicidal activity in macrophages activated by recombinant gamma interferon. Infection and Inmuniti 59:521-528, 1991. 